Rabaska

Revue d'ethnologie de l'Amérique française

\title{
Folklore et ethnologie (Université de Sudbury)
}

\section{Daniela Moisa}

Volume 18, 2020

URI : https://id.erudit.org/iderudit/1072963ar

DOI : https://doi.org/10.7202/1072963ar

Aller au sommaire du numéro

Éditeur(s)

Société québécoise d'ethnologie

ISSN

1703-7433 (imprimé)

1916-7350 (numérique)

Découvrir la revue

Citer ce document

Moisa, D. (2020). Folklore et ethnologie (Université de Sudbury). Rabaska, 18, 447-449. https://doi.org/10.7202/1072963ar d'utilisation que vous pouvez consulter en ligne.

https://apropos.erudit.org/fr/usagers/politique-dutilisation/ 


\section{Folklore et ethnologie}

Département de Culture et communication

Université de Sudbury

Sudbury (Ontario)

P3E 2C6

Téléphone : (705) 673-5661

Télécopieur : (705) 673-4912

Courriel :dmoisa@usudbury.ca

Toile : www.usudbury.com

\section{Projets de recherche}

Depuis cette année, plusieurs projets de recherche et d'enseignement ont pris naissance dans le cadre du programme de Folklore et d'ethnologie de l'Université de Sudbury. Le point commun de ces projets est la volonté d'accorder une attention particulière aux approches pédagogiques s'inspirant de l'apprentissage expérientiel, démarche qui est très importante, surtout pour nos étudiants étrangers et pour le développement des communautés locales.

1. Pour le semestre d'hiver 2020, les étudiants inscrits au cours de folklore FoLK 3516 Enquête ethnographique ont consacré environ 200 heures chacun à un projet pilote visant à intégrer dans la structure du cours des méthodes spécifiques à l'apprentissage expérientiel. Intitulé « Patrimoines connectés : valorisation, médiatisation et vivreensemble », le projet avait comme principaux objectifs de placer les étudiants dans divers environnements socioculturels afin de vivre une expérience personnelle les amenant à connaître et à comprendre le concept de patrimoine, ses significations, formes, fonctions et enjeux éthiques. Quatre communautés ethnoculturelles de la région ont été choisies pour ce projet expérimental : la communauté franco-ontarienne de Sudbury, la communauté anglophone de Capréol, la communauté autochtone de Dokis et la communauté congolaise du Grand-Sudbury. Le choix des communautés a été fait en fonction du profil et des intérêts des étudiants inscrits dans le cours. Leurs recherches et projets ont été réalisés en collaboration avec quatre organismes culturels et patrimoniaux à but non lucratif : le Centre franco-ontarien de folklore, le Northern Ontario Railroad Museum et l'Heritage Center situés à Capréol, et le Dokis Museum de Dokis First Nation. Les étudiants devaient faire leur apprentissage sous la forme d'un va-et-vient entre la salle de classe et les communautés partenaires. Leur travail auprès des organismes culturels et des communautés a été chapeauté par l'enseignant du cours et par la plateforme virtuelle Riipen, qui facilite l'apprentissage microexpérientiel, en connectant étudiants, organismes à but non lucratif et partenaires industriels. Pendant deux mois, les étudiants ont appris à prendre contact avec les communautés, à les apprivoiser. Ensuite, ils ont identifié des sujets liés au thème proposé et choisi les personnes-ressources qui les ont aidés à construire leurs projets. Ils ont effectué des entrevues filmées sur le terrain avec des porteurs de patrimoine, pris des photos et obtenu le matériel nécessaire à la création d'une exposition multimédia sur chaque communauté à des fins de valorisation et de médiatisation. L'objectif principal de ce projet était de faire vivre aux étudiants une expérience d'immersion de type ethnographique, de leur faire apprendre et expérimenter des méthodes spécifiques à l'ethnographie. En plus des aspects méthodologiques, d'autres objectifs, théoriques, devaient être atteints : comprendre les définitions du patrimoine culturel, les enjeux et les défis liés à son étude, sa valorisation et sa mobilisation 
en contexte de diversité ethnoculturelle - francophone, anglophone, autochtone et allophone ; travailler et monter des projets de développement culturel, patrimonial et muséal avec et dans n'importe quelle communauté ; saisir l'importance du patrimoine culturel immatériel en vue de la réconciliation avec les communautés autochtones, du vivre-ensemble dans la diversité, de l'intégration harmonieuse des communautés immigrantes francophones au nord de l'Ontario ; permettre aux étudiants de tisser des liens avec les communautés et les organismes culturels locaux et régionaux. Les méthodes de formation proposées par le cours et mobilisées par les étudiants ont combiné l'apprentissage par l'expérience, l'immersion et la coopération.

2. Le deuxième projet intitulé « L'objet immatériel : raconter, faire, connecter le monde. Atelier d'apprentissage expérientiel » a été mené avec les étudiants en folklore et ethnologie et en collaboration avec la professeure Crina Bud du Collège Glendon (Université York). Le premier objectif de l'atelier était de créer un environnement d'apprentissage expérientiel bilingue et interdisciplinaire permettant aux étudiants de comprendre le pouvoir qu'ont les objets : de connecter les gens et de créer des ponts entre les langues, les cultures, les expériences de la migration, les histoires de vie. Le patrimoine culturel immatériel, la littérature, l'ethnologie performative se sont donné la main pour instaurer un cadre où les étudiants ont pu se révéler et s'écouter, en participant à deux exercices complémentaires : la présentation créative et libre d'un objet personnel et significatif pour leur trajet personnel et familial ; le tissage d'interprétations, d'images, de textes et de gestes performatifs à partir d'un objet « banal », proposé par les organisatrices des deux ateliers. Le deuxième objectif des deux ateliers a été de confronter les deux groupes et de porter une réflexion globale sur la manière dont l'expérience, la langue, la culture animent le monde matériel et la société. Ce projet sera prochainement présenté au colloque international Création et complicité. L'atelier artistique comme espace d'expression et de dialogue, organisé à l'Université Laval.

3. Le troisième projet de recherche de collaboration se déroule dans le cadre de l'École d'été en Habitat écologique, paysage culturel et développement local organisé à Cacica, Roumanie, en collaboration avec Carmen Chasovschi de l'Université Stefan cel Mare de Suceava. Ce projet a comme principal objectif la sensibilisation des étudiants, des chercheurs, de la population générale et des autorités locales par rapport à la valeur et à l'importance sociales et environnementales des maisons ancestrales. Un autre objectif est de transmettre l'importance de la connaissance et de la préservation des techniques de construction vernaculaires en tant que stratégies douces et responsables de développement local. C'est une occasion aussi de mobiliser et partager les méthodes spécifiques à l'apprentissage expérientiel dans un contexte socioculturel autre que québécois. L'année passée, la thématique de l'école, « Maisons connectées - valorisation et développement local », a ressemblé des étudiants de plusieurs universités roumaines, ainsi que des chercheurs des institutions de recherche locales et a permis la rénovation puis la transformation d'une maison traditionnelle tombée en ruine en un lieu communautaire. Durant l'été 2020, dix étudiants canadiens projetaient passer deux semaines en Roumanie, une première dans le programme de 
Folklore et ethnologie et, plus largement, dans la fédération Laurentienne ; ce voyage d'étude est reporté à l'année 2021 en raison de la crise de la CovID-19. En plus d'être complètement dépaysés, les étudiants canadiens devaient faire leur apprentissage sur le terrain par immersion dans la société d'accueil et en collaboration directe avec les communautés, les représentants des autorités locales ainsi que des étudiants roumains avec lesquels ils devaient former des équipes tout au long de leur séjour.

\section{Programmation et inscriptions}

La programmation en folklore et ethnologie continue de s'enrichir avec la rédaction de nouveaux cours en ligne, à distance et en classe. Il s'agit du cours FolK 2306 Cultures et communication (en ligne), FoLK 1XXx Introduction aux cultures numériques (à distance), FolK 2xxx Études critique des minorités : concepts et théories (en ligne). Malgré ces réalisations, les inscriptions en folklore et ethnologie et, plus largement dans les cours en langue française en Ontario, restent un défi, surtout dans une situation financière institutionnelle précaire à laquelle vient de s'ajouter la crise sanitaire. Malgré ces défis, nous continuons à améliorer notre programmation en français, en créant des cours en patrimoine numérique, en ethnologie de l'espace, en ethnologie et communautés, et à renforcer nos liens avec les communautés locales et le milieu universitaire national et international. 